\title{
COBERTURAS E IDENTIDADES: UMA REFLEXÃO SEMIÓTICA SOBRE A MÁSCARA EM ENSOR
}

Vivian Mendes Lopes

\begin{abstract}
RESUMO
O trabalho discute o papel da máscara na pintura de Ensor, sobretudo a maneira como o componente identitário - velado e (re)construído por essa figura - participa da estrutura discursiva em que esta se apresenta. A reflexão é conduzida à luz da semiótica greimasiana e de um modelo semiótico de identidade (LANDOWSKI, 2002), que é aplicado à análise da obra $A$ Intriga.
\end{abstract}

PALAVRAS-CHAVE: máscara; semiótica; identidade

\section{Introdução}

ste artigo $^{1}$ tem por objetivo refletir sobre o papel da figuratividade, isto é, o patamar superficial do percurso gerativo de sentido (GREIMAS, 1986), nas obras do pintor belga James Ensor (1860 - 1949) que trazem a máscara como elemento estético. Inspiradas nas máscaras do carnaval flamengo, as máscaras figuradas nos trabalhos de Ensor caracterizam-se pela marca do exagero, pelo aspecto caricato e grotesco, chegando, muitas vezes, a beirar o absurdo e o irreal: uma mistura de traços humanos, animalescos e fantasmagóricos. Dada essa excentricidade, essas máscaras parecem criar um

1 Os elementos de base para o desenvolvimento deste artigo foram delineados em uma monografia realizada, em 2006, para curso 'Conceitos fundamentais em Semiótica Plástica', do Programa de Pós-Graduação da UFF, ministrado pela professora Lucia Teixeira, a quem devo agradecimento por me haver possibilitado explorar, naquele texto, o objeto/questionamento então levantado com maior riqueza e senso de coesão. 
mundo particular, não só no que diz respeito ao universo figurado na tela, mas também na própria trajetória temática do artista, marcando uma ruptura com um estilo de caráter mais realista que orienta suas primeiras obras.

Não se pode dizer, no entanto, que essa inovação temática corresponda a uma mudança definitiva de técnica expressiva. Ao manter os traços de uma figuratividade que parece se caracterizar mais pela aproximação ao icônico do que ao abstrato, Ensor confere a essas máscaras certo apelo representativo ou "impressão referencial” (GREIMAS, 1986, p. 7). O tratamento icônico (BERTRAND, 2003) das máscaras parece instalar fraturas no jogo da referenciação (impedir a identificação dos indivíduos mascarados) e, simultaneamente, multiplicar seus efeitos (figurar novos corpos), devido à natureza vacilante do referente para onde apontam essas figuras: o disfarce. Ao que parece, as máscaras compelem o espectador a um jogo de referenciação que é no mínimo duplo e que, por promover o ocultamento/forjadura dos indivíduos representados, toca a temática da identidade. Ou mesmo, em certo sentido, a leitura dessas máscaras parece performatizar o próprio processo de construção da identidade, sobretudo quando a consideramos como uma prática semiótica em situação - a atribuição de sentido à presença do Outro, conforme sugere Landowski (2002).

Partindo de tal consideração, o trabalho procura discutir de que maneira o componente identitário - simultaneamente velado e reconstruído pela máscara - participa da estrutura discursiva em que essas figuras se apresentam. Conforme a própria linguagem empregada na construção do objeto de estudo é reveladora, o referencial de base para o desenvolvimento da reflexão é a semiótica de orientaçáo greimaisiana ${ }^{2}$. Para conduzir o estudo, percorremos

2 Conforme expóe Barros (2002, p. 187-188), a semiótica greimasiana procura explorar os mecanismos e procedimentos que constroem os sentidos do texto, em qualquer natureza de expressão. No que tange ao tratamento dos procedimentos discursivos, a semiótica postula a interdependência dos planos da expressão e do conteúdo e concebe este último como um percurso gerativo de sentidos. Esse percurso caminha de relaçóes semânticas mais simples e abstratas a relaçóes mais complexas e concretas, que se manifestam na superfície do texto. $\mathrm{O}$ percurso abrange os níveis fundamental (constituído por uma oposição semântica simples e abstrata - o conteúdo geral do texto), narrativo (organiza-se do ponto de vista de um sujeito) e discursivo (concretiza a organização narrativa por procedimentos de temporalização, espacialização, actorialização, tematização e figurativização). Os termos da oposição semântica do nível fundamental podem ser eufóricos ou disfóricos e afirmados ou negados (nisto consiste a sua sintaxe elementar). Esses traços podem ser representados/visualizados 
um procedimento metodológico que coincide com a ordem de apresentação das seçóes deste trabalho. Inicialmente, discutiremos brevemente o papel das máscaras no conjunto temático/figurativo da obra de Ensor, situando-as no percurso de produção artística do pintor. Em seguida, refletiremos sobre a máscara do ponto de vista da figuratividade e seus efeitos de referenciação (GREIMAS, 1986), atentando para os elementos dessa relação que apontam para o tema da identidade. Dessa forma, apresentaremos o conceito de identidade com que estamos trabalhando, depreendido do modelo semiótico proposto por Landowski (2002). Finalmente, com base no conjunto de questôes levantadas, analisaremos a obra $A$ Intriga, destacando de que maneira as articulações entre os seus planos de expressão e de conteúdo apontam para temática identitária, que a figura da máscara parece revestir.

\section{Ensor e as máscaras}

Pintor belga do final do século XIX, James Ensor apresenta uma obra complexa, que caminhou em direção a um estilo de tendência expressionista (BECKS-MALORNY, 2000, p. 61). Artista de formação acadêmica, Ensor se dedicou, inicialmente, a uma pintura de caráter mais realista, período em que suas obras logo se destacaram pela presença de um estilo pessoal. Este se caracterizava pela maneira particular como o pintor explorava a luz sobre tons escuros, deformando as linhas e criando uma atmosfera ora melancólica ora agressiva, que viria a culminar nas máscaras (BECKS-MALORNY, 2000, p. 16). Em linhas gerais, a trajetória de produção de Ensor parece se organizar ao longo de três grandes eixos: uma primeira fase de tendência mais realista; uma segunda caracterizada pelo imaginário, marcada pela presença da máscara; e uma terceira, de orientação mais satírica e caricaturesca.

O que estamos chamando aqui de produção 'mais realista' se refere a obras que exploram temas da vida cotidiana: pinturas de paisagem, que retratam os ambientes da cidade e do campo, naturezas mortas e pinturas de inte-

no espaço de um modelo operacional - o quadrado semiótico - que mapeia as articulaçóes lógicas de uma dada categoria semântica: relaçôes horizontais de contrariedade e verticais de complementaridade. Essas relaçóes delimitam os limites conceituais de uma dada categoria semântica. A discussão que o trabalho propóe está mais diretamente relacionada aos níveis fundamental e discursivo do percurso gerativo. Em diversos pontos da análise o modelo do quadrado semiótico será explorado como importante recurso operacional. 
rior, que exploram o espaço doméstico como ambiente de práticas diversas (a leitura, o chá da tarde, o descanso, entre outras). Já as obras atravessadas pelo traço a que nos referimos como 'imaginário' constituem aquelas que começam a refletir uma progressiva mudança no tratamento que pintor dá a esses temas, revestindo-os com um tom sombrio, exagerado, grotesco e fantástico, sobretudo pela presença da figura da máscara.

Inspiradas no folclore belga, as máscaras de Ensor inauguram uma ruptura com os temas de inspiração mais realista de sua fase academicista (BECKS-MALORNY, 2000, p. 38). A primeira obra em que aparece essa figura data de 1883. Em As máscaras escandalizadas, reproduzida na prancha 1, a máscara surge como um adorno sobreposto às faces das personagens representadas. Em obras posteriores, entretanto, a máscara e a fantasia/vestimenta constituem a própria cena pintada e sugerem uma fusão com os rostos e corpos que lhes dão suporte. Dessa forma, Ensor constrói e evoca o imaginário mantendo o tratamento icônico das figuras: inaugura um mundo novo a partir de figuras bizarras, porém reconhecíveis, uma vez que estas guardam semelhanças com os objetos do mundo concreto, como podemos ver na pintura $A$ morte e as máscaras, de 1897, reproduzida na prancha 2.

O ponto máximo dessa "expressão cheia de agudeza" (ENSOR, s. data, citado em BECKS-MALORNY, 2000, p. 57), atributo que o próprio pintor conferia às suas máscaras, foi, ao que parece, o desenvolvimento da caricatura - elemento característico da fase a que estamos chamando de 'satírica'. Conforme salienta Becks-Malorny (2000, p. 79), as obras marcadas pela presença da caricatura possuem o traço da crítica social explícita, atacando, sobretudo juízes, médicos e padres. Esse aspecto temático, assim como a própria caricatura como figura que o reveste, foge ao escopo desta reflexão, pois sinaliza mais nitidamente a identidade da figura representa. Desta forma, importa destacar que esta breve apresentação da mudança temática no percurso da vida artística do pintor permite construir foco sobre o tema do disfarce (identidade ocultada/forjada), que ganha força com a entrada da figura da máscara no conjunto da produção de Ensor. 
Prancha 1: As máscaras escandalizadas

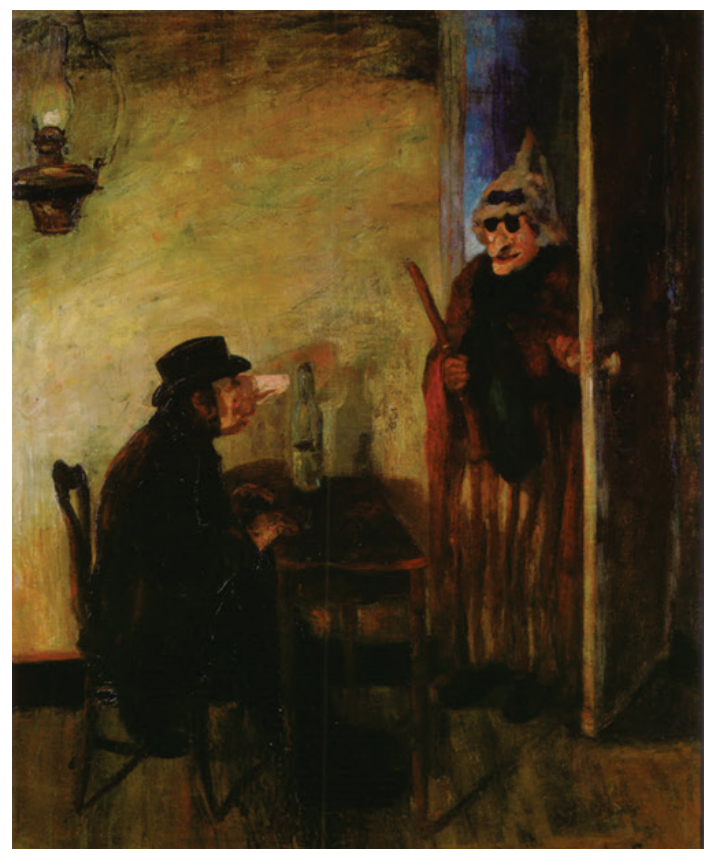

Prancha 2: A morte e as máscaras

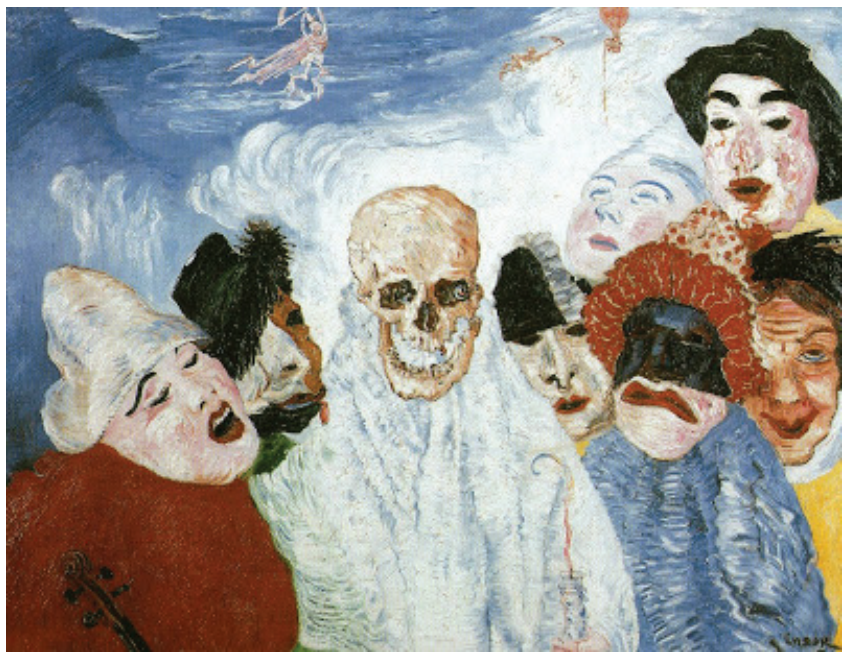




\section{As máscaras e o duplo jogo da referenciação}

Situada no nível mais superficial do percurso gerativo greimasiano (BARROS, 2002, p. 188), a figuratividade ocupa o topo de uma hierarquia responsável pela construção do sentido: encobre os temas sugeridos pelos enunciados de ação ou de estado que, por sua vez, narrativizam as oposiçôes fundamentais do nível mais profundo. Reformulada em termos de distância, no que se refere aos participantes da enunciação, em um texto plástico, a figuratividade seria a instância mais próxima do espectador, a via de entrada para a construção do sentido em um mundo artificialmente produzido. Conforme expóe Bertrand (2003, p. 211), a figuratividade pode ser manipulada de diferentes formas: manifesta-se em uma escala cujas polaridades são a iconicidade, caracterizada pela densidade elevada dos traços figurativos e pelo forte efeito de referenciação, e a abstração, em que esses aspectos se apresentam de forma contrária.

É pela figura da máscara que penetramos no universo criado por Ensor em boa parte de suas obras. É ela que salta aos olhos do espectador e o convida a participar do jogo da construção do sentido. Essa figura, entretanto, apresenta um caráter ambivalente. Por um lado, suspende a identificação do sujeito-suporte como um objeto do mundo natural, interpondo-se entre este e o espectador. Por outro, dada à natureza icônica (BERTRAND, 2003) ${ }^{3}$ de sua configuração expressiva, instaura uma instância independente desse suposto sujeito-suporte. Assim, para construir as identidades das figuras representadas, o espectador é levado a operar com as marcas expressivas que lhe são dadas. Dessa forma, a fantasia se autonomiza, desprendendo-se de seu suporte e passando a valer por ele. Nesse segundo nível da referenciação, não parece interessar descobrir quem é o sujeito que, por detrás da máscara, se esconde, mas, ao contrário, analisar os traços da própria vestimenta, que o encobre, uma vez que é a vestimenta o elemento que se atualiza, de maneira mais evidente, no plano da expressão.

3 Segundo Bertrand, a diferença semântica entre o icônico e o abstrato é construída não só em termos da densidade dos traços que compóem um formante figurativo, como também da densidade das redes associativas com outros formantes. Para o autor, ocorre iconicidade quando os traços reunidos por um formante permitem "sua interpretaçáo como representante de um objeto do mundo natural” (BERTRAND, 2003, p. 201). 
Ao nos deixarmos sensibilizar pelos elementos de composição desses formantes, somos invadidos por uma profusão de cores fortes e iluminadas, que as preenchem e lhes conferem formas e contornos exagerados. A essa forma de expressão, associam-se impressóes referenciais que, dentro do quadro axiológico de nossa cultura, parecem revestir os temas do disfarce e da encenação: figuras de apelo humano combinadas a traços bricolados de palhaços, pierrôs, monstros, bonecos e fantoches emergem das ritmadas camadas de cores que preenchem e animam um cenário bastante particular.

No entanto, esse segundo nível da referenciação, ao mesmo tempo em que acata representaçóes de objetos do mundo real, não os toma por inteiro, mas os fragmenta e os recombina. Continuamos, assim, a apreciar um mundo extraordinário, do qual nos aproximamos, pelo reconhecimento de marcas representativas de uma realidade conhecida e, simultaneamente, nos afastamos, uma vez que esse reconhecimento se dá apenas de maneira parcial. Essas máscaras não são homens, não são bonecos nem são monstros, exclusivamente, mas a mistura de tudo isso, em maior ou menor grau. Assim, ainda que possamos agrupar essas figuras em uma unidade, sob o signo 'fantasias', na tentativa de identificá-las, o termo, por seu caráter generalizante, apagaria uma série de traços que as distinguem uma das outras.

Dessa forma, isto é, porque inaugura uma rede de referentes internos, a iconicidade das máscaras de Ensor, no lugar de "resolver" o problema da identificação dos indivíduos representados, parece, ao contrário, convidar o espectador a participar ativamente da construção dessas figuras. É assim que a figura máscara, como objeto que oculta e revela, parece revestir o tema da identidade, não só sua força simbólica, mas, sobretudo, pela dinâmica interpretativa a que compele o espectador: a de incitar a atribuição de sentido a um dado formante pela mediação dos demais formantes em presença. A seguir, apresentaremos a concepção semiótica de identidade segundo Landowski (2002), que enfatiza o seu caráter situacional (construída em ato) e interacional (mediante a presença do Outro), e, dessa forma, mostra-se consoante com as consideraçóes aqui desenvolvidas.

\section{A identidade como construção semiótica}

Landowski (2002, p. 4) concebe o sujeito, individual ou coletivo, como uma grandeza que se define a partir de sua identidade. Assim como outras 
grandezas semióticas, também o sujeito é visto como uma unidade que se constitui pelo reconhecimento de uma diferença que o separa das demais grandezas a ele associadas. Desse modo, o sujeito se constitui sempre em presença de um Outro, o seu dessemelhante. No entanto, conforme afirma o autor (2002, p. 4), para se construir o estatuto do sujeito, não basta que essa diferença seja meramente reconhecida, é necessário também que ela sofra um investimento semântico, ou seja, é necessário que se inicie o processo de sua semiotização:

Com efeito, o que dá forma à minha própria identidade não é só a maneira pela qual, reflexivamente, eu me defino (ou tento me definir) em relação à imagem que outrem me envia de mim mesmo; é também a maneira pela qual, transitivamente, objetivo a alteridade do outro atribuindo um conteúdo específico à diferença. Assim, quer a encaremos no plano da vivência individual ou (...) da consciência coletiva, a emergência do sentimento de "identidade" parece passar necessariamente pela intermediaçáo de uma alteridade a ser construída. (LANDOWSKI, 2002, p. 4)

No que diz respeito aos grupos sociais, a própria natureza híbrida dos espaços socioculturais fornece um conjunto de traços diferenciais "exploráveis para significar figurativamente a diferença posicional que separa logicamente o Um de seu Outro" (LANDOWSKI, 2002, p. 13). Sendo o Outro um elemento estrangeiro em relação ao Nós de referência, a diferença promove duas políticas contrárias entre si: a aceitação do Outro (na condição de que ele perca as marcas que o fazem estrangeiro e assimile os hábitos da cultura de referência); ou a sua exclusão, fundamentada na crença da impossibilidade de integração no grupo de referência.

É nesse sentido que se diz que a diferença posicional lógica entre o Nós e o Outro não está dada a priori, mas se constrói semioticamente no seio de uma dada cultura. Por essa razão, Landowski (2002, p. 16) aponta que, para além das relações fundamentadas no reconhecimento das diferenças, é possível também estabelecer outras formas de interação com as figuras do Outro, estas fundamentadas no reconhecimento das semelhanças entre as duas partes 
(partes do Outro no Nós e partes do Nós no Outro). A partir dessa concepção, ampliam-se as formas de articulação entre o Nós e o Outro.

Dessa forma, o autor (2002, p. 16) postula existência de, pelo menos, duas maneiras por meio das quais o sujeito pode conceber sua identidade: (1) negativamente, ou seja, por oposição a um Outro, a qual seria manifestada pelas políticas de assimilação (conjunção) e exclusão (disjunção); e (2) positivamente, ou seja, pela afirmação de algo que lhe é próprio e que, talvez, compartilhe com o Outro, princípio que orienta as políticas de segregação (não conjunção) e admissão (não disjunção), de que trataremos a seguir. A articulação entre esses termos - os diferentes modos de tratamento do Outro - pode ser ilustrada no modelo do quadrado semiótico, apresentado no quadro 1.

Quadro 1: modos de tratamento do Outro

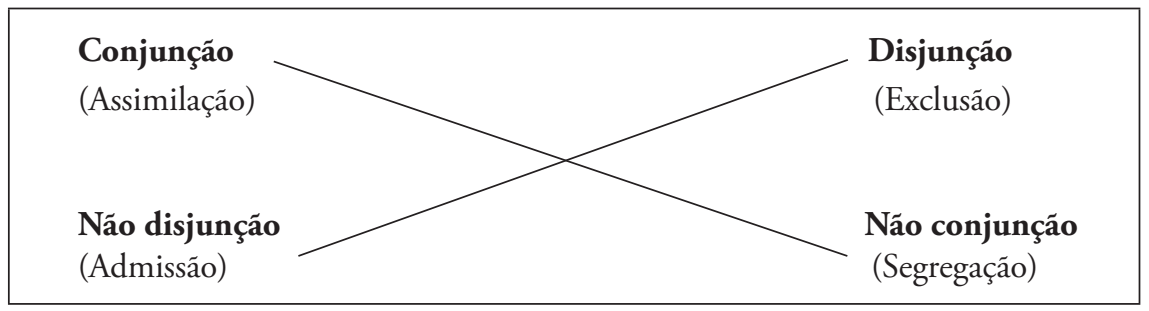

Para Landowski (2002, p. 11) as interações com base nas dessemelhanças envolvem estratégias de construção de estereótipos, o que confere caráter estático e estável tanto ao Outro quanto ao Nós de referência. Por outro lado, ao se definir positivamente, o sujeito abre espaço para relaçóes mais dinâmicas e complexas com o seu Outro e com o próprio grupo de referência. Isso implica a instabilidade das relaçóes intersubjetivas: cada novo encontro do Nós com o seu Outro envolve a redefinição dessas relaçóes.

É esta lógica que orienta as políticas de segregação e admissão. Os dispositivos segregativos, ou não conjuntivos, apesar de rejeitarem a mistura de unidades consideradas distintas, reservam um lugar para o Outro na esfera sociocultural do grupo de referência. Essas práticas, portanto, buscam ser menos disjuntivas do que sugere a atitude de exclusão, pois se baseiam no princípio de uma unidade original entre as partes, que o grupo de referência faria um esforço em manter. Já os dispositivos de admissão, ou a não disjunção, têm como 
base a coexistência entre as partes, partindo do pressuposto de estas haverem sido separadas e objetivando a reaproximação. As práticas de admissão visam, portanto, à resistência ao princípio da assimilação, desejando a presença do Outro no seio do grupo de referência, sem que isso signifique a redução do diverso ao uniforme, uma vez que admitem a ideia de autonomia entre as partes.

As bases negativa e positiva de semiotização da identidade, assim como as quatro possíveis políticas que manifestam essas bases, servem ao trabalho como parâmetros à interpretação sobre papel semiótico das máscaras na obra A Intriga, submetida à análise/leitura, conforme apresentaremos mais adiante. A inclusão desse quadro teórico no contexto de nossa discussão se justifica pela sua visão da construção identitária como uma dinâmica que é conduzida pelo estabelecimento de relaçóes entre os elementos em presença. A nosso ver, o ponto de contato entre esse quadro de reflexão e a problemática da máscara reside sobretudo na questão de que, para abordar o segundo plano da referenciação (aquele em que as máscaras se autonomizam), e assim lhes atribuir sentido/identidade, o espectador é levado a operar ativamente com a rede de referentes internos da obra. Em outras palavras, o processo de semiotização empreendido pelo espectador na identificação das máscaras parece reproduzir, numa pequena esfera, as estratégias identitárias que empreendemos diariamente nos nossos encontros com o Outro ${ }^{4}$.

\section{A intriga}

O filáo interpretativo levantado na seção anterior foi explorado na análise da obra A Intriga (1890) $)^{5}$, reproduzida na prancha 3. A análise partiu da observação das regularidades formais da materialidade semiótica, procedendo ao inventário do conjunto de traços significantes que sugeriam relaçóes homó-

4 Dentro da perspectiva que estamos adotando, a semiotização pode ser vista como um procedimento inerente à leitura de qualquer objeto artístico. No entanto, no que se refere a uma obra que traz a própria figura da máscara no seu nível mais superficial, podemos supor que essa dinâmica se reflita também no nível de suas estruturas mais profundas.

5 A escolha dessa pintura se deveu ao fato de esta ser considerada a obra que marca o fim de um estilo, a antecipaçáo de traços expressionistas, podendo ainda ser vista como uma obra de tom "realista" (BECKS-MALORNY, 2000, p. 61). Esse traço nos interessa, uma vez que acreditamos que este seja um dos fatores responsáveis pelo efeito simultaneamente concreto e fugidio das figuras mascaradas. 
logas entre os planos da expressão e do conteúdo. Identificou-se, assim, a rede de referentes internos das máscaras ali afiguradas. Em seguida, com base na observação dessas relaçooes, realizou-se a análise/leitura do plano do conteúdo, a qual pareceu reforçar a participação do tema da identidade em sua estrutura discursiva. A seguir, detalharemos os pormenores dessa discussão.

\section{Prancha 3: A Intriga}

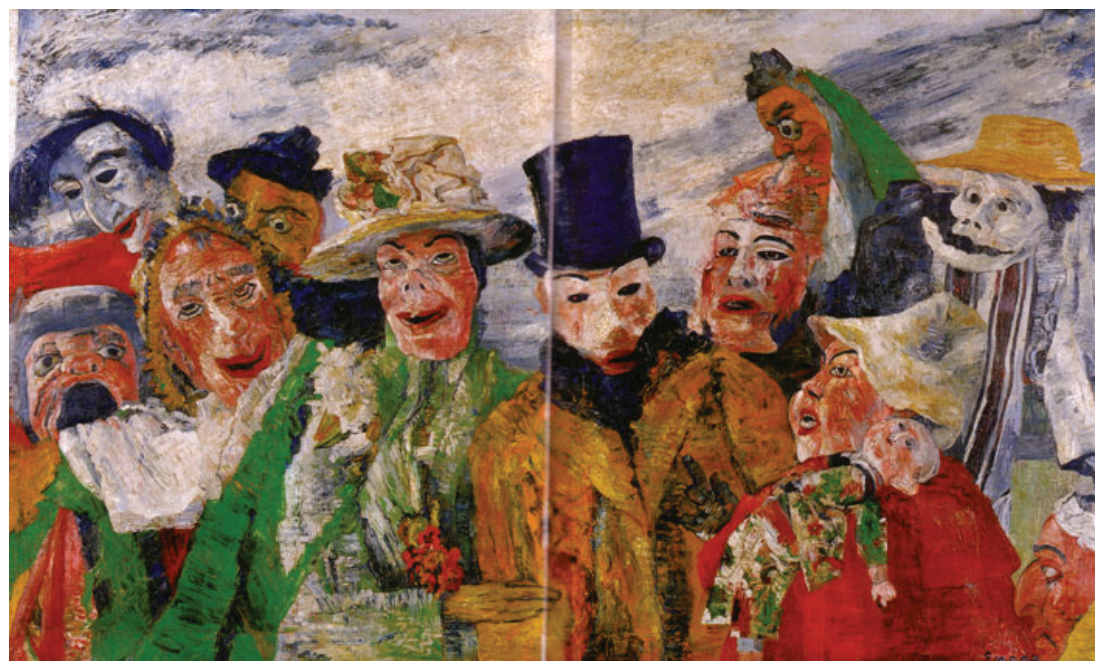

\section{Plano da expressão}

Ao olhar rápido, $A$ Intriga se apresenta como uma composição de equilíbrios e constâncias. As pinceladas bruscas e ritmadas, por exemplo, se espalham por toda a área da tela. Além disso, o preenchimento de toda a composição repousa sobre a retomada regular de quatro cores fundamentais: o vermelho, o ocre, o verde e o azul ${ }^{6}$. Essas cores, mais puras e concentradas em determinadas posiçóes da tela do que em outras - as três primeiras mais concentradas na base e a última na altura de uma linha imaginária paralela à base que dividiria o quadro ao meio - parecem distribuir-se por outras partes

6 Apesar de identificarmos a presença do branco, adotamos o procedimento analítico de não o considerar uma cor de base, uma vez que, na pintura em análise, ele parece ser bastante explorado como recurso para iluminar e mesclar as quatro cores fundamentais da composição. 
do quadro. Além disso, com a participação do branco, essas cores se partem em mesclas e adquirirem nuances, que reforçam a impressão de harmonia e regularidade no conjunto da tela.

Uma apreciação mais cuidadosa permite iniciar a identificação de contrastes plásticos. Porque a cor constitui um traço bastante explorado na pintura em análise, tomaremos a categoria cromática (GREIMAS, 1986, p. 1) para anunciar um primeiro contraste, ao que chamaremos de 'colorido/neutro'. O termo 'neutro' designa aqui não a ausência de cor, mas uma escolha cromática de fundo, sobre a qual as demais cores pareçam contrastar, ganhando mais intensidade e vibração. Na pintura em questão, esse termo parece ser atualizado pelo azul escuro. Realizando o outro polo do contraste, o colorido, encontramos as cores vermelha, ocre e verde, carregadas de pulso e energia.

O contraste colorido/neutro tem como referência as cores de base da composição, e, dessa forma, constitui uma categoria não graduável (GREIMAS, 1986, p. 1). Entretanto, como dissemos acima, as quatro cores de base aparecem atualizadas tanto em estado mais compacto e homogêneo, quanto, principalmente, em tons mais difusos e nuançados, sobretudo pela entrada do branco em pinceladas ritmadas que diluem a cor de base. Dessa forma, verifica-se um segundo par de contraste cromático na composição, este de natureza graduável: o contrate puro/mesclado. Os dois pares de contrastes destacados até aqui podem ser agrupados em um quadrado semiótico, ilustrado no quadro 2. Como se pode observar, os termos contrários, equivalentes às quatro cores de base, correspondem ao termo 'puro'; e seus contraditórios, equivalente ao branco, corresponderiam ao termo "mesclado", graças ao efeito que essa cor produz sobre as demais.

\section{Quadro 2: articulaçóes da cromaticidade}

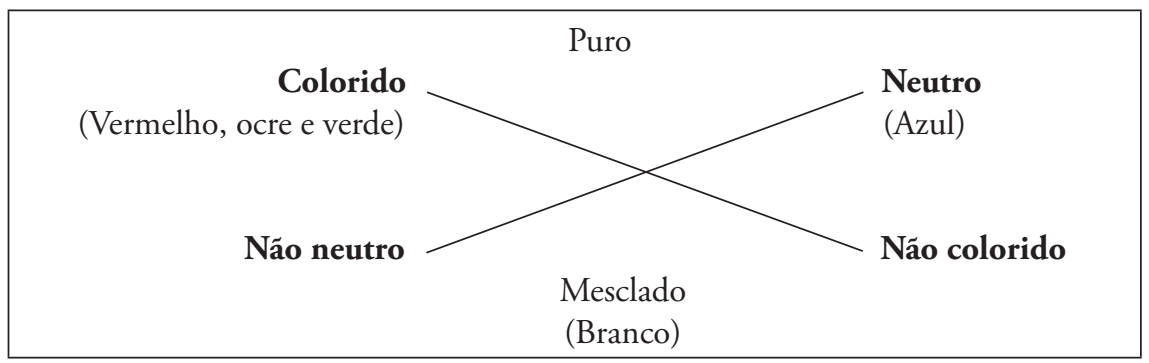


Como vemos, a articulação entre os contrastes colorido/neutro e puro/ mesclado mapeiam a realização dos constituintes cromáticos no conjunto da composição. O contraste colorido/neutro, entretanto, parece constituir elemento central do plano da expressáo: a partir dele pode-se apreciar um contraste de natureza topológica (GREIMAS, 1986, p. 2), referente a disposição das configuraçóes plásticas no espaço da tela. Como veremos mais adiante, o contraste topológico constituiu o ponto de partida para a semantização da composição. A articulação entre os contrastes das categorias cromática e topológica pode ser verificada quando observamos a distribuição geral do contraste colorido/neutro no espaço da tela.

$\mathrm{O}$ arranjo das cores que realizam o contraste colorido/neutro delimita duas linhas que dividem a tela em unidades topológicas: uma área superior e outra inferior. $\mathrm{O}$ azul (escuro, de caráter mais puro) compóe uma faixa arqueada, mais ou menos à altura da gola da personagem de cartola, posicionada um pouco mais à direita do centro da tela. Essa faixa tem curvatura ascendente e delimita / "contém", na porção superior da tela, predominantemente o termo náo colorido, realizado pelo tom azul mesclado, tal como ilustra o quadro 3 .

Quadro 3: divisão topológica superior

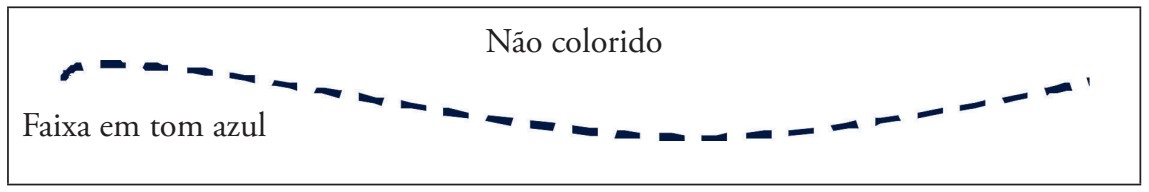

Interseccionando-se com essa faixa azul, verificamos uma outra linha arqueada à altura da máscara à direita da personagem de cartola, formando um arco de curvatura descendente, conforme a ilustração do quadro 4. Esse arco é composto por uma sequência de unidades preenchidas de vermelho (porçóes correspondentes às bocas das máscaras e a algumas peças das vestimentas) e parece conter, na porção inferior da tela, predominantemente, os termos colorido e não neutro, que correspondem respectivamente ao vermelho, ocre e verde, de tendência mais pura, e à realização dessas mesmas cores em tons mesclados. 


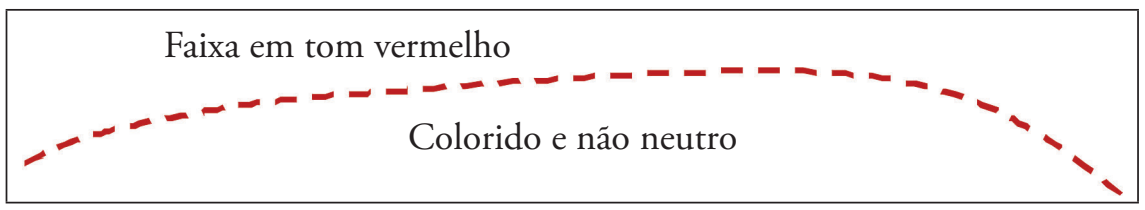

Assim, o contraste colorido/neutro, associado ao contraste baixo/alto da categoria topológica, demarca duas unidades distintas na tela. Essas unidades, porém, estão apenas parcialmente cercadas: as linhas que as delimitam não são contínuas, além disso, as massas cromáticas que essas linhas "contém" extravasam e permeiam o outro domínio (tanto há porçôes de neutro no domínio inferior quanto há porções de colorido e não neutro no domínio superior). Dessa maneira, além de se ver uma separação entre as partes que compóem a pintura, veem-se também elementos que confundem/suspendem essa divisão, sobretudo se observarmos o uso do branco, que se distribui por quase toda a extensão da composição. Essas duas unidades de natureza topológica, ainda que parciais, forneceram base à semantização da composição, isto é, a análise do seu plano de conteúdo. Como veremos a seguir, as figuras que compóem cada uma das unidades topológicas foram analisadas do ponto de vista dos dois níveis de referenciação de que tratamos anteriormente.

\section{Plano do conteúdo: primeiro nível de referenciação}

No domínio superior da tela, atualizado pelo termo neutro do contraste cromático, reconhecemos figuras como o céu, máscaras de aparência fantasmagórica, partes de vestimentas e alguns assessórios de adorno. Já no domínio inferior, atualizado pelo polo colorido do contraste, vemos máscaras de aparência mais humanizada e suas vestimentas que, a julgar pelo casal que ocupa a posição central do quadro, lembram trajes e objetos de festa (roupas de casamento, um possível buquê, etc.). Essa configuração sugere um contraste semântico inicial. O domínio inferior, por remeter à imagem da vida social, à maneira como nos apresentamos no mundo e à noçáo de civilização poderia ser designado como 'terreno', associando-se esse termo à esfera do real, humano, e conhecido. Por oposição, o domínio superior parece associado à noção do 'etéreo', articulada à esfera do fantástico, do não humano e do desconhecido. Esses contrastes podem ser dispostos no modelo do quadrado semiótico, 
reproduzido no quadro 5 . Nessa representação, além da associação dos contrários terreno/etéreo aos domínios topológicos da pintura, destacamos também os elementos homologáveis aos seus respectivos complementares. Assim, ao 'não etéreo' associamos as máscaras de aparência mais real/humana, e ao 'não terreno', as máscaras de aparência fantástica.

Quadro 5: articulações da referenciação externa

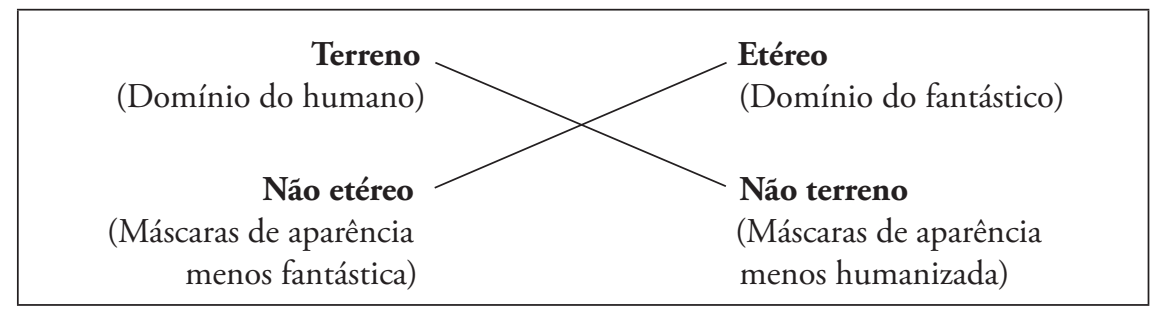

Esse contraste inicial nos parece fundamental, uma vez que abre ao espectador portas de entrada na obra, por força de sua identificação com um dos domínios em jogo. Assumamos, por exemplo, que o espectador tome a via do terreno (o que reflete o caminho tomado pela analista), identificando-se com as máscaras de aparência mais humanizada. Isso implica que, ao passar ao segundo nível da referenciação, estará assumindo que este seja o seu grupo de referência - o grupo do Nós, nos termos propostos por Landowski (2002). Dessa forma, de acordo com o princípio da relação entre os termos, esse espectador encontrará no domínio do fantástico o seu Outro. Em outras palavras, a alteridade será semantizada a partir do referencial assumido. Passemos, assim, à discussão sobre essa dinâmica de identificação/semiotização.

\section{Plano do conteúdo: segundo nível de referenciação}

Nesta etapa da análise, inventariamos o conjunto de referentes internos que diferem os dois domínios entre si. Esses referentes internos constituem os traços diferenciais a partir dos quais podemos construir a identidade das figuras do domínio de referência (o terreno), e, por extensão, a das próprias figuras do domínio superior, o nosso Outro. O ponto de partida para esse investimento semântico foi o contraste plástico colorido/neutro. As formas 
preenchidas pelo termo neutro (as porçóes correspondentes, da perspectiva da primeira referenciação, às máscaras/vestimentas fantásticas, em tom de azul, situadas mais às laterais direita e esquerda da tela) parecem menos contrastadas do que as formas do termo colorido. Temos a sensação, por exemplo, de que essas figuras confundem-se, diluem-se, "perdem" suas massas para aquela grande massa azul de mesclado. $\mathrm{O}$ mesmo não se pode dizer das figuras preenchidas pelo termo colorido (ocre, verde e vermelho), mais contrastadas e contidas em seus limites.

Para investir semanticamente nessa diferença, retomamos o contraste terreno/etéreo, agora não mais associando-o à noção referencial externa de humanidade, mas à noção interna da integridade material dos corpos afigurados. Organizados no modelo do quadrado semiótico, como se pode observar no quadro 6, esses de elementos assim são distribuídos: (1) os contrários terreno e etéreo foram associados, respectivamente, ao domínio de formas mais contidas, compactas, corpóreas e tangíveis, e ao domínio amorfo ou das formas diluídas, dispersas, não tangíveis, fugidias e expansivas; e (2) seus pares de complementares foram associados às figuras de limites menos diluídos, situadas no domínio inferior da tela (não etéreo), e às figuras menos contidas em seus limites, posicionadas mais ao domínio superior da tela (não terreno).

Quadro 6: articulações da referenciação interna

(Domínio de formas contidas)
Náo etéreo

Mapeada nos termos do quadrado acima proposto, a obra pode ser contemplada com base no parâmetro dos modos de tratamento do Outro: o princípio relacional de construção identitária desenvolvido por Landowski (2002). Nesse nível da análise, o critério que fundamenta nossa identificação com o domínio do terreno é definido com base nos traços formais que o diferenciam do domínio do etéreo: a individualidade dos corpos. Desse modo, uma das formas possíveis de construirmos semanticamente nosso domínio 
de referência seria a da exclusão desse Outro e do mundo que ele evoca: essa esfera do fugidio, do menos concreto, do imaterial, intangível e etéreo - um mundo que, à primeira vista, desconhecemos, o lugar do nosso dessemelhante. Afinal, nossos corpos nos conferem limites, nos individualizam, permitindo que nos reconheçamos como uma unidade.

Ao mesmo tempo, se consideramos que, na pintura, tanto o domínio do terreno quanto o do etéreo, assim como os elementos neles dispostos, não são formas plenamente contidas, veremos que o Outro e o grupo de referência estão "perto demais" para serem vistos como totalmente distintos. Em outras palavras, as regularidades formais que aproximam as duas instâncias entre si sugerem também uma dinâmica de identificação que esteja fundamentada na semelhança entre os grupos.

Segregação ou admissão? Ao que parece, não podemos dizer qual dessas duas atitudes estamos empreendendo quando atingimos esse nível de tratamento do Outro, ou seja, a partir do ponto de vista das semelhanças. Para tanto, teríamos de passar ao nível narrativo do percurso gerativo, em que poderíamos verificar as modalizaçóes que interferem nas açóes e no modo de existência do sujeito (neste caso, nós mesmos, identificados com alguma personagem particular do quadro) na sua relação com o Outro. Esse empreendimento, no entanto, foge ao escopo neste estudo. Desse modo, o que nos parece mais importante ressaltar é que, ao reconhecermos traços formais de aproximação entre os dois domínios afigurados, podemos assumir que um dos sentidos da obra, na sua cobertura mascarada, possa ser lido pelo viés da instabilidade do projeto identitário e da natureza dinâmica de sua experienciação nos encontros com o Outro ${ }^{7}$.

7 E quanto à assimilação? Uma leitura possível é associá-la ao destino das figuras do grupo inferior, como metáfora do tema da morte, por exemplo, subtraindo a materialidade das figuras do domínio terreno e integrando-as ao domínio do etéreo. Esta interpretação, entretanto, nos parece precipitada, porque se baseia apenas em uma articulação lógica da categoria semântica de corporeidade (neste caso, a sua perda), com que estamos trabalhando neste plano da análise. Por outro lado, é no mínimo curioso observar que, o movimento de assimilação, na medida em envolve uma dinâmica de subtração dos limites (uma "desindividuação"), também aponta para o caráter transitório dessas configurações identitárias: nesse caso, o deixar de ser. Ou seja, também nesse ponto, que, por sua orientaçáo de estado/fazer, demandaria a exploração do nível narrativo, a temática da identidade como instância em permanente devir parece também se insinuar. 


\section{Considerações finais}

$\mathrm{Na}$ análise da obra $A$ Intriga, as articulaçóes entre os planos da expressão e do conteúdo apontaram para o contraste axiológico elementar terreno vs. etéreo. Nos dois níveis de referenciação da pintura, as figuras parecem revestir o tema da identidade. No plano da referenciação velada, fundamentada em um contrato de "impressão referencial" entre os enunciadores (GREIMAS, 1986, p. 7), as máscaras/vestimentas que recobrem a face das personagens sugerem uma oscilação conceitual entre o humano e o fantástico. No segundo plano de referenciaçáo, fundamentado na observação da rede de referentes internos à obra, o processo de identificação das figuras se realiza por meio da própria identificaçấo do espectador com um dos termos do contraste axiológico elementar. Na leitura aqui desenvolvida, a adoçáo do polo terreno como grupo de referência levou à semiotização do conjunto de diferenças e semelhanças dos formantes plásticos das máscaras/vestimentas como uma oscilação conceitual entre o contido e o diluído (a categoria semântica da corporeidade).

As categorias humano/fantástico e contido/diluído são, portanto, variaçôes conceituais, nos dois planos de referenciação, do contraste axiológico elementar do plano do conteúdo - terreno vs. etéreo. Porque as variaçôes conceituais se sobrepóem, as articulaçóes lógicas do contraste axiológico elementar terreno vs. etéreo se multiplicam. Em outras palavras, os traços semânticos/ identificadores das máscaras são complexos e dinâmicos. Esses traços nem são apresentados todos em um único nível de referenciação e nem são estáveis, sobretudos os de segundo nível, pois sua própria semiotizaçáo depende da porta atravessada pelo espectador pintura adentro: a via do terreno ou a do etéreo. São essas diferentes possibilidades de relação do espectador com as máscaras figuradas na pintura analisada que realçam a marca identitária dessas coberturas figurativas.

Ao que parece, a relação entre o espectador e a obra constitui uma metonímia do processo de semiotização que este empreende com as figuras do mundo, a partir do qual sua própria identidade se constrói/reconstrói. Esse traço reforça o aspecto de encenação sugerido pela figura da máscara, que convida o espectador a experienciar o jogo da vida em uma esfera menor, no espaço da tela. Pelo intermédio das figuras mascaradas, apontadas para fora da 
pintura, o espectador é convidado a entrar no jogo da construção do sentido. No entanto, para habitar esse mundo, ele é levado operar com o conjunto das máscaras afiguradas e a participar da construção ativa de quem são e dos sentidos que evocam.

\section{Referências}

BARROS, Diana Luz Pessoa de. Estudos do discurso. In: FIORIN, J. L. (org.) Introduçâo à linguística: II. São Paulo: Contexto, 2002. p. 187-219.

BECKS-MALORNY, Ulrike. James Ensor: as máscaras, o mar e a morte. Lisboa: Taschen, 1999.

BERTRAND, Denis. Caminhos da semiótica literária. Bauru, SP: EdUSC, 2003, p. 207-231.

FLOCH, Jean-Marie. Um nu de Boubat: sémiotique poétique et discourse mythique em photographie. In: Petites mythologies de l'oeil et de l'esprit: pour une sémiotique plastique. Paris, Amsterdam: Hadès Benjamins, 1985, p. 21-38.

GREIMAS, Courtés. Dicionário de semiótica. São Paulo: Cultrix, s.d.

GREIMAS, Courtés. Sémiotique 2: dictionnaire raisonné de la théorie du language. Paris: Hachette, 1986.

LANDOWSKI, Eric. Presenças do outro. Tradução de Mary Amazonas Leite de Barros. São Paulo: Editora Perspectiva, 2002. p. 1-25

TATIT, Luiz. Abordagem do texto. In: FIORIN, J. L. (org.) Introdução à linguística: I. Sáo Paulo: Contexto, 2002. 187-209.

TEIXEIRA, Lucia. Leitura de textos visuais na escola. Comunicação apresentada no III Encontro Franco-brasileiro de Análise do Discurso. Rio de Janeiro. UFRJ, 1999b. mimeo. 


\title{
COVERINGS AND IDENTITIES: A SEMIOTIC REFLECTION ON ENSOR'S MASKS
}

\begin{abstract}
This paper discusses the role of the mask in Ensor's paintings, attending to how identity - as an element which is concealed and (re)construed by this figure integrates the discourse structure where it is presented. The discussion is situated within the semiotics of A. J. Greimas and applies a semiotic model of identity (LANDOWSKI, 2002) to the analysis of the painting The Intrigue.
\end{abstract}

KEY-WORDS: mask; semiotics; identity

Recebido em: 31/10/2014 Aprovado em: 22/02/2015 